the other three strains a slight to moderate attack. It is worth noting that while the Irish commercial strain was severely attacked in 1943, only a slight to moderate attack ensued in 1944; and if this be taken as a basis for comparison, an idea is furnished as to the possible reaction of the other strains under more pronounced manganese-deficient conditions.

This study has, therefore, shown that different grasses react differently to manganese deficiency; further, the effect applies to different strains of at least one grass. The fact that the 1943 investigation was carried out under conditions similar to those which obtained in the previous investigations with different varieties of oats, wheat and barley ${ }^{2}$ enables a comparison to be made of the relative sensitivity to manganese deficiency of these latter crops and the grasses used. This reveals that, depending on species and strain, some grasses may be practically as sensitive to manganese deficiency as the more sensitive oat and wheat varieties, and much more so than the least sensitive of these. Further research in this connexion is proceeding.

I wish to thank Dr. Jenkins and Prof. Caffrey for providing grass seeds, and Dr. P. H. Gallagher for advice.

Soil Science Department,

Thomas Walsh.

University College,

Dublin.

Feb. 1.

${ }^{-2}$ Imp. Bureau of Soil Science, Tech. Comm., No. 39 (1940).

"Gallagher, P. H., and Walsh, T., J. Agric. Sci., 33, 197 (1943).

\section{Induction of Heat in Spayed Femate Guinea Pigs by Subcutaneous Hormonal Implants}

DurING estrus in the guinea pig, there is a relative hyperæmia at the antimesometrial border of the bicornate uterus ${ }^{1}$, and after suitable hormonal treatment similar vascular changes have been induced in the spayed animal ${ }^{2,3}$. Vaginal cornification, increase in uterine weight, and all the histological features so far recognized of a typical heat response can be elicited in spayed female guinea pigs by a simple administration of ostrogens, but the cyclic vascular change is only displayed after preliminary priming of the animals with small daily injections of oestradiol monobenzoate $(0.0005 \mathrm{mgm}$. for six days $)$ followed by a large daily dose $(0.5 \mathrm{mgm}$.) for two days and a final injection of progesterone $(0 \cdot 2 \mathrm{mgm}$.). We believe that this antimesometrial hyperæmia in the spayed female guinea pig is not a simple manifestation of estrogenic activity, but only becomes evident when a hormonal balance approximating to the physiological condition of normal œstrus has bren obtained. It is further significant that this antimesometrial hyperæmia is a response of the adult uterus and cannot be induced in the immature guinea pig by either oestrogenic ${ }^{4}$ or gonadotropic ${ }^{5}$ stimula. $^{-}$ tion.

The method of hormonal administration by the subcutaneous implantation of pellets, introduced by Deansley and Parkes ${ }^{6}$, seemed to us to offer an attractive labour-saving alternative to the daily injections, by which the animal would receive a small but continuous dosage with the minimum disturbance.

One $2 \mathrm{mgm}$. œstradiol pellet was inserted subcutaneously by means of a large intravenous needle in each of twelve adult spayed guinea pigs. Invariably the vagina opened on the third day following the insertion of the pellet, and maximum cornification of the vaginal smears occurred on the sixth day. After six days, half the number of animals were given a subcutaneous injection of $0.2 \mathrm{mgm}$. progesterone, and the other half were similarly treated on the twelfth day. The animals were killed three hours after the progesterone injection. In every case the uterus was enlarged and œedematous, with a thickened endometrium showing tortuous glands here and there dilated with secretion. These œestrous reactions were particularly well marked in the 12-day group of animals. There was, however, never any antimesometrial hyperæmia-a constant feature of the guinea pig uterus during normal œstrus. In an odd uterine section of the 12-day group a localized hyperæmia could be seen on one or other side or at the mesometrial border. We had apparently failed to obtain the necessary hormonal balance to promote the normal vascular change.

It is reasonable to assume that the inevitable fibrous encapsulation of the pellet would impose a decreased rate of absorption. At first there would be a fairly constant rate of absorption with a dosage too high for priming, and then a downward gradient, finally flattening out to a reduced dosage-level. Some such absorption curve is also suggested by Folley ${ }^{7}$. In the normal cycle, on the other hand, ostrogenic activity rises from minimum to maximum, to attain its peak around ovulation time. The priming dose of $0.0005 \mathrm{mgm}$. in our former experiments ${ }^{2}$ did not produce vaginal opening until the sixth day, and was then followed by large doses. Because of its more gradual, more prolonged and culminating high level of œstrogenic stimulation, this method, we be lieve, conforms more closely to the physiological gradient of hormonal activity during the cestrous cycle.

It can therefore be concluded that $(a)$ the pellet method can provoke all the well-known vaginal and uterine reactions. It cannot, however, elicit the cyclic vascular change (antimesometrial hyperæmia), which provides a particularly delicate test of the complete uterine response to stimulation, but requires for its onset a preliminary sensitization followed by a nicely balanced quantitative interplay of cestrogens and progesterone. (b) The pellet method possesses undoubted advantages where the desired effect can be obtained by the administration of hormones over a long period, for example, to feminize experimentally the plumage growth of the brown Leghorn capon, physiologically to induce lactation in the cow, and clinically in the treatment of infantile uterus.

We have to acknowledge our thanks to Messrs. British Schering, Ltd., and also Organon Laboratories, Ltd., for kindly providing us with supplies of progesterone and fused œstradiol pellets respectively.

$$
\text { P. BACSIOH. }
$$

Department of Anatomy,

G. M. WYBURN.

\section{University of Glasgow.} Feb. 2. \footnotetext{
${ }^{1}$ Bacsich, P., and Wyburn, G. M., Trans. Roy. Soc. Edin., 60, 79,
Pt. i (1940).

${ }^{2}$ Bacsich, P., and Wyburn, G. M., Trans. Roy. Soc. Edin., 80, 465, Pt. ii (1941).

3 Bacsich, P., and Wyburn, G. M., J. Endocrin., 3, 401, No. 4 (1944).

4 Bacsich, P., and Wyburn, G. M., Proc. Roy. Soc. Edin., Sect. B, 61, 188, Pt. ii (1942).

${ }^{5}$ Bacsich, P., and Wyburn, G. M., J. Anat., 77, 118, Pt. i (1942).

- Deansley, R., and Parkes, A. S., Proc. Roy. Soc., B, 124, 279 (1937).

7 Folley, S. J., Proc. Roy. Soc., B, 132, 142 (1944).
} 